\title{
Peripheral stimuli generate different forms of inhibition of return when participants make prosaccades versus antisaccades to them
}

\author{
Ralph S. Redden ${ }^{1} \cdot$ Matthew D. Hilchey ${ }^{1,2} \cdot$ Raymond M. Klein $^{1}$
}

Published online: 16 August 2016

(C) The Psychonomic Society, Inc. 2016

\begin{abstract}
Inhibition of return (IOR) is usually viewed as an inhibitory aftermath of visual orienting typically seen in the form of slower responses to targets presented in a previously oriented to location. As shown by Taylor and Klein (2000. Journal of Experimental Psychology: Human Perception and Performance, 26, 1639-1656), the nature of the inhibitory effects resulting from an uninformative cue seem to be contingent on the activation state of the oculomotor system. Here we contrast target discrimination performance following either a prosaccade or antisaccade in the spatial cueing paradigm. Our findings suggest that the level of activation of the reflexive oculomotor system determines the dynamics of the inhibitory effect, wherein an effect nearer to the input end of processing is observed when the reflexive oculomotor system is actively suppressed, and an effect nearer to the output end of processing is observed when the reflexive oculomotor system is actively engaged. These effects interact differently with the Simon effect— providing converging evidence that they are dissociable inhibitory phenomena.
\end{abstract}

Keywords Orienting · Inhibition of return · Simon effect · Cueing $\cdot$ Information processing dynamics

Slower response times (RTs) to cued relative to uncued locations have been documented in the aftermath of both overt (i.e., with eye movements) and covert (i.e., without eye

Ralph S. Redden

rredden@dal.ca

1 Department of Psychology \& Neuroscience, Dalhousie University, 1355 Oxford st., 3rd Floor LSC, Halifax, NS B3H 4R2, Canada

2 Department of Psychology, University of Toronto, 100 St. George Street, 4th Floor, Sidney Smith Hall, Toronto, ON M5S 3G3, Canada movements) orienting in the spatial cuing paradigm. This phenomenon is commonly referred to as inhibition of return (IOR; Posner \& Cohen, 1984; Posner, Rafal, Choate, \& Vaughan, 1985). A growing number of findings have shown that IOR can be fundamentally altered by whether or not eye movements are made. Kingstone and Pratt (1999) found reduced IOR when measured in the presence of distractor stimuli for covert, but not overt, orienting. Hunt and Kingstone (2003) demonstrated that IOR in the context of overt orienting interacts with the gap effect but not target luminance, whereas IOR in the context of covert orienting interacts with target luminance but not the gap effect. Sumner, Nachev, Vora, Husain and Kennard (2004) have shown IOR in the context of covert orienting but not for overt orienting when using visual stimuli that bypass the superior colliculus. Gabay, Henik and Gradstein (2010) reported IOR for covert orienting responses in patients with Duane Retraction Syndrome, but only in visual fields in which they were capable of making eye movements. Patients with left hemifield neglect exhibit a deficit in IOR for right-sided targets in the context of covert orienting, but not overt orienting (Bourgeois, Chica, Migliaccio, de Schotten, \& Bartolomeo, 2012). Relatedly, the right intraparietal sulcus and temporo-parietal junction are critical for IOR for right-sided targets in the context of covert orienting, but not overt orienting (Bourgeois, Chica, Valero-Cabre, \& Bartolomeo, 2013). It has been shown that whereas visuospatial working memory is critical for IOR in the context of covert orienting, it is not in the context of overt orienting (Zhang \& Zhang, 2011).

Klein and Hilchey (2011) offered a framework for organizing the numerous dissociations in the literature. When the task is strictly covert, slower RTs are observed principally when the cue and target occupy the same or proximal locations (Taylor \& Klein, 2000; Fischer, Pratt, \& Neggers, 2003; Hilchey, Klein, \& Satel, 2014). This effect is commonly 
referred to as attentional/perceptual (Taylor \& Klein, 2000) or, synonymously, as occurring nearer the input end of the processing continuum (Hilchey, Hashish, MacLean, Ivanoff, Satel, \& Klein, 2014). When overt orienting is required, subsequent responding is biased against the location of the cue. As such, repeat stimulation of an input pathway is not required to observe the effect (see also Posner et al., 1985) which can be measured with stimuli in central vision requiring responses compatible with the location of the peripheral cue (Taylor \& Klein, 2000; Rafal, Egly, \& Rhodes, 1994). This effect is commonly referred to as motoric/decisional (Taylor \& Klein, 2000), or as occurring nearer the output end of the processing continuum (Hilchey, Klein, \& Ivanoff, 2012). Taylor and Klein (2000) deduced from these patterns that the form of inhibition following a spatially uninformative cue (i.e., one that does not predict the location of subsequent events) is contingent upon whether eye movements are made. Despite these dissociations, both of these inhibitory cueing effects are commonly referred to as inhibition of return (IOR).

Relatively recent investigative work has focused on identifying how the two forms of IOR — output and input — differentially affect manual non-spatial discrimination of visual stimuli. Placed in a broader historical context, early research suggested that IOR was limited to target detection and localization responses (see Klein \& Taylor, 1994, for review; Terry, Valdes, \& Neill, 1994); however, as first demonstrated by Hartley and Kieley (1995) and later reinforced by Lupiáñez et al. (1997), IOR can be reliably measured in non-spatial discrimination tasks at cue-target onset asynchronies greater than $400 \mathrm{~ms}$. Non-spatial discrimination tasks - unlike localization or detection tasks - have the added benefit of permitting meaningful analysis of both RT and accuracy. In the context of the input/ output dichotomy of IOR, accuracy is particularly analytic because, as illustrated by Ivanoff, Klein and Lupiañez (2002), the two hypothesized forms make different predictions about IOR effects when these are plotted in speed-accuracy tradeoff (SAT) space (Fig. 1). The form of inhibition that expresses itself as a response or decision bias should delay responding without directly affect the quality of input information leading to the decision (Fig. 1B, left green (dashed) arrow). Thus, outputbased inhibition should result in a speed accuracy tradeoff (conditions with slower responses will have higher accuracy). In contrast, the form of inhibition that expresses itself as attentional or perceptual should impede sensory or sensorimotor processing (Fig. 1B, red (solid) arrow). Thus, input-based inhibition should result in a genuine reduction in the efficiency of information processing (Ivanoff \& Klein, 2006; see Ivanoff, Klein, \& Lupiañez, 2002, for review).

Investigations demonstrating delayed responding to or processing of previously cued targets in discrimination tasks since Hartley and Kieley (1995) have shown a high degree of variability in the effect of IOR on accuracy; indeed, a metaanalysis of 67 measurements reveals no clear pattern (see
Fig. 2). A recent investigation, however, offers a clue for explaining this between-experiment variability. Chica, Taylor, Lupiañez and Klein (2010) used eye monitoring and manipulated, between subjects, whether or not an eye movement was required toward a spatially uninformative peripheral cue that preceded a to-be-discriminated peripheral color target.

Two qualitatively different patterns emerged for the two cue-response conditions. When eye movements were expressly forbidden, responding was slower and less accurate to targets at the cued location, supporting an input-based attribution. However, when eye movements were required to the cue, responding was slower but more accurate at the cued location, a pattern that converges on the output-based attribution made by Taylor and Klein (2000) and Posner et al. (1985).

Although the nature of the inhibition is modulated by whether the task involves eye movements toward stimuli, we question whether the output-based inference of Taylor and Klein (2000) generalizes to all instances of overt orienting (Klein \& Hilchey, 2011; Hilchey, Dohmen, Crowder, \& Klein, 2016). For instance, an overt orienting response may be made toward (prosaccade) or away from (antisaccade) a peripheral onset. At both the empirical and theoretical level, we have reason to believe that inhibition, when generated in the context of antisaccades, is input-based. The empirical basis of our belief comes from studies in which observers are required to generate antisaccades. These studies almost exclusively show that the inhibitory effect can only be measured when the cue and target are presented in the same location (Rafal, Egly, \& Rhodes, 1994; Fecteau, Au, Armstrong, \& Munoz, 2004). The theoretical basis lies in the proposal (e.g., Forbes \& Klein, 1996) that observers must inhibit the reflexive oculomotor system in order to behave according to instructions in the antisaccade task, a proposal for which there is support at the single unit level (see Everling, Dorris, Klein, \& Munoz, 1999 and Ignashchenkova, Dicke, Haarmeier, \& Thier, 2004). On the basis of these behavioral and neurophysiological findings Klein and Hilchey (2011) proposed a more refined account of the two forms of inhibitory effect seen in Taylor and Klein (2000). They suggested that the nature of the inhibitory aftereffect is contingent not on whether eye movements are or are not made, but rather on the activation state of the reflexive oculomotor system. When the reflexive oculomotor system is suppressed the input form is generated; when it is not suppressed the output form is generated.

The results from the prosaccade condition in Chica et al. (2010) converge on our theoretical conceptualization of the output form of IOR. However, we believe this finding is worthy of replication in order to verify the robustness of the effect, as well as extend the result to other non-spatial two-alternative forced-choice (2-AFC) tasks (e.g., from color to form). In the present experimental design, at the time of the cue - as in Chica et al.- one group will be required to generate a prosaccade and return to fixation before the target. A second 
A

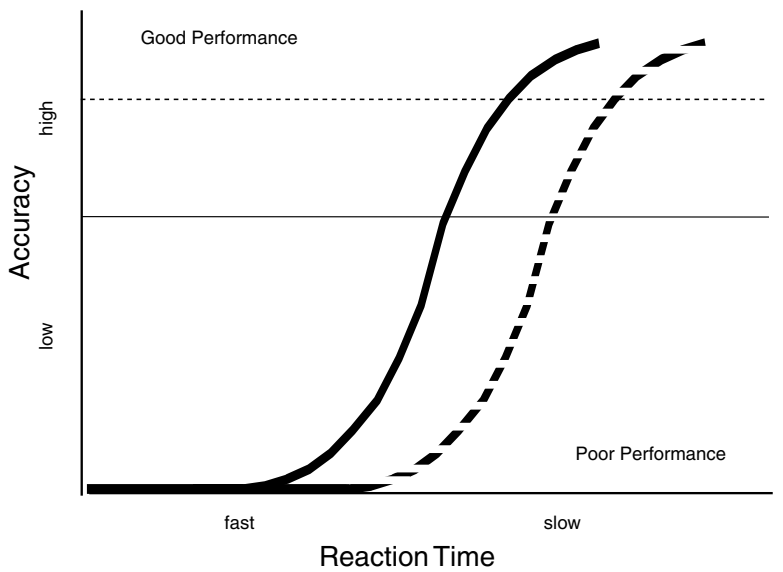

Fig. 1 Illustration of the two theories of IOR. All functions represent hypothetical rates of information accrual where improvement in the accuracy of performance as response time increases; participants are responding to targets that appear and are neither masked nor removed. If the RT delay associated with IOR is caused a genuine deterioration in performance, this would result in a rightward shift of the function (as
B

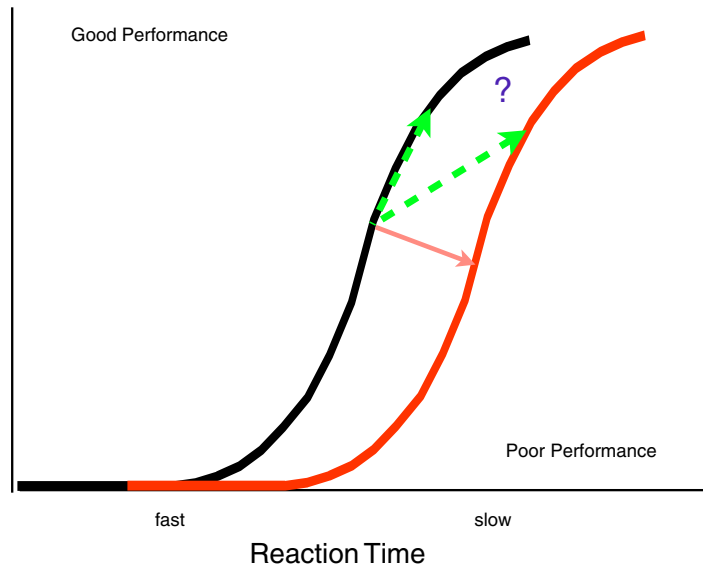

shown by: A, solid to dashed function; $\mathbf{B}$, the red (solid) arrow) or a change in slope of the function (not depicted in this figure). Another possible pattern, where observers demonstrate slower but more accurate responding (also referred to as a speed-accuracy trade-off or criterion shift), is represented (A, solid to dashed horizontal lines; $\mathbf{B}$, as shown by green arrows) group will be required to generate an antisaccade. We expect to replicate the speed-accuracy tradeoff pattern reported by Chica et al. (2010) in the condition for which observers are required to make a prosaccade response to the peripheral cue. Two predictions remain for the heretofore untested antisaccade condition. On one hand, if the output effect is generated by all overt orienting responses (as induced by
Taylor \& Klein, 2000), then an SAT would be expected (slower but more accurate responding at the cued location). However, if it is the state of the reflexive oculomotor system that determines the nature of the effect (Klein \& Hilchey, 2011; Hilchey, Klein, \& Satel, 2014), then an input effect would be expected at the location of the cue (as in Chica et al.'s 'ignore' condition).
Fig. 2 A meta-analysis of 67 conditions (19 studies, see Appendix A) for which inhibited RT was observed at cued locations in a non-spatial two-alternative forced choice (2-AFC) task (Redden, 2016). Each arrow represents the results of an individual SOA within an experiment, where the arrow starts at performance for 'Uncued' targets and ends as performance for 'Cued' targets. The net vector (average results from all 67 measurements) is represented by the red (thicker) arrow

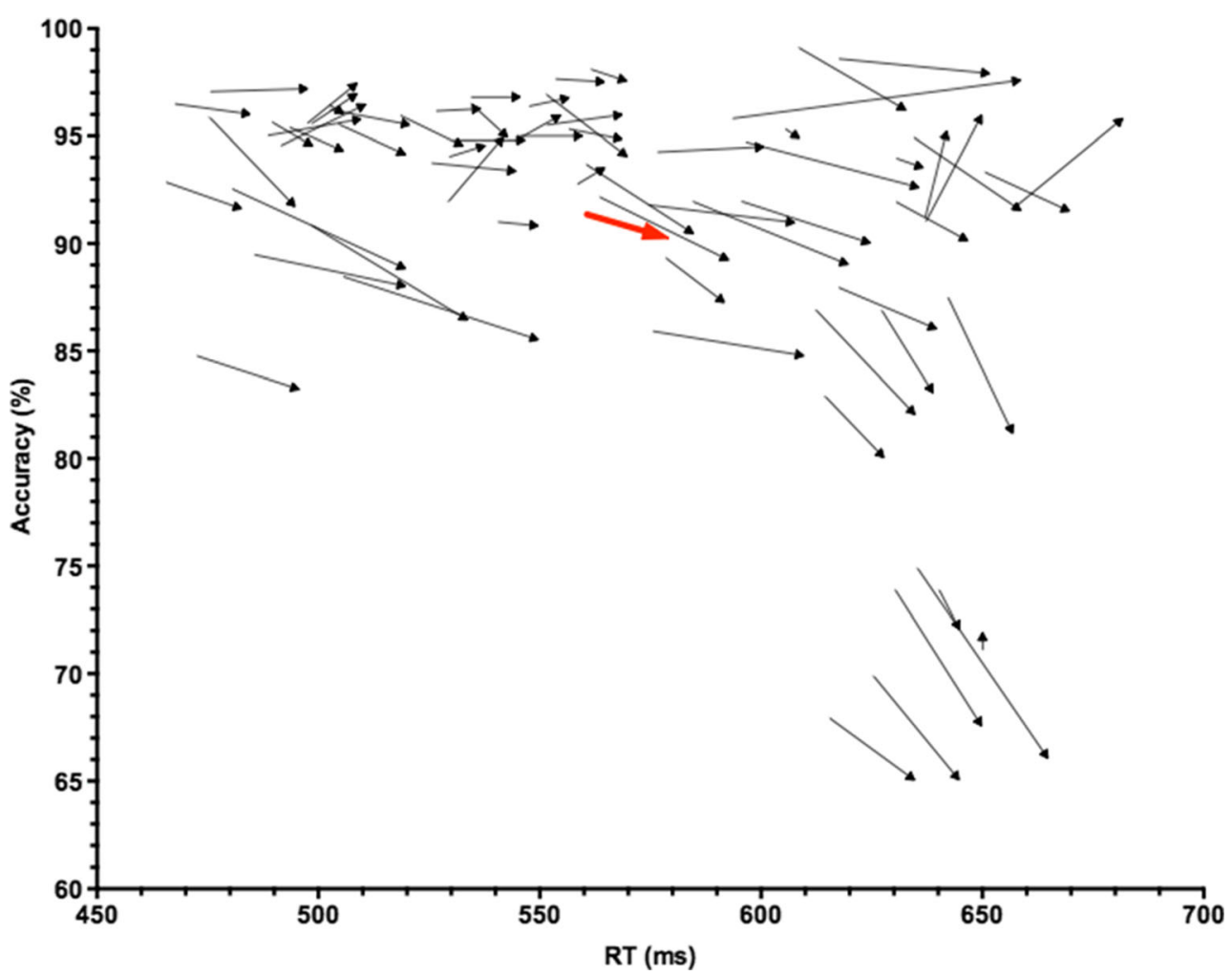




\section{Method}

\section{Participants}

Fifty-nine (31 Anti; 28 Pro) naive observers (16 male; 5 lefthanded) ranging in age from 18 to 51 participated in the study for course credit in one 60-min session. This was the number of participants required in order to obtain data for 20 observers in each group after exclusion criteria (see Results). This is a larger sample size per condition than the principal investigations we wish to extend (Chica et al., 2010; Hilchey et al., 2016), so as to ensure sufficient power to replicate these effects. All observers were recruited from the undergraduate subject pool at Dalhousie University.

\section{Apparatus and procedure}

The experiment was run in a dimly lit room on a 19" CRT monitor. Eye positions were monitored by EyeLink II headmounted equipment. Trials began with the presentation of three black placeholder boxes $[1.5 \times 1.5$ degrees visual angle (DVA)] separated horizontally by 6.2 DVA on a gray background. The center box contained a black ' + ' $(0.5$ DVA $)$ as a fixation stimulus. Trials began with a drift correction that required the observer to fixate the central stimulus and press the space bar. If the observer was not accurately fixating the central stimulus, no further visual events would occur and a tone would alert them to refixate. If the observer successfully fixated the central stimulus, a circle measuring 0.9 DVA would appear surrounding the fixation stimulus and remain on the screen for the duration of the trial. Two hundred fifty milliseconds (ms) after the appearance of the circle, one of the lateral placeholder boxes flashed. The flash was created by filling the empty space in the placeholder box with gray. This stimulus lasted $90 \mathrm{~ms}$ and was not spatially predictive of any future events in the trial. Observers in the prosaccade condition were required to generate a saccade to the stimulated placeholder box and back to the fixation stimulus. Observers in the antisaccade condition were required to generate a saccade to the unstimulated placeholder box and back to the fixation stimulus. Trials on which inaccurate or early eye movements occurred were terminated and recycled. Feedback about eye movement performance was also given on these trials. Once successful eye movements to the first signal had been executed, observers were required to maintain fixation for the duration of the trial. A target was presented in one of the lateral placeholder boxes (50\% left, $50 \%$ right) $1,000 \mathrm{~ms}$ after the onset of the cue. The target was equally likely to be either a ' + ' or an ' $\mathrm{x}$ ' within a circle (1.3 DVA). Observers were required to make a speeded manual response to indicate the target identity by pressing either the ' $\mathrm{z}$ ' or ' ' ' key. Observers completed one practice block of 32 trials followed by a single experimental block of 200 trials. The sequence of events in a trial is represented in Fig. 3.

\section{Results}

In the prosaccade condition, trials on which the eye movement to the cue was not executed within 1.5 DVA of the cued peripheral placeholder were excluded from analysis $(M=22.2 \%)$. In the antisaccade condition, trials on which the first saccade was executed toward the cued placeholder (an incorrect prosaccade) were excluded from analysis ( $M$ $=28.3 \%$ ). Trials in which eye movements occurred after the presentation of the target but before the manual response were excluded from analysis $(M=12.2 \%)$. After these oculomotor criteria were established, 18 observers who failed to complete at least half of the trials were excluded from analysis $($ Pro $=8$; Anti $=10)$. One additional observer in the antisaccade condition who performed the discrimination task with zero errors was also excluded. ${ }^{1}$ Based on a histogram of the remaining RTs, responses faster than $300 \mathrm{~ms}(0.2 \%)$ and slower than $1,200 \mathrm{~ms}$ $(1.5 \%)$ were excluded from analysis. A two-sample $t$-test on eye movement RT revealed, as expected, that antisaccades $(316 \mathrm{~ms})$ were generated more slowly than prosaccades $(262 \mathrm{~ms})[t(38)=4.28, p<0.001]$.

Mixed $2 \times 2$ analyses of variance (ANOVA) were conducted on each dependent variable (speed and accuracy) with the factors of Cueing (within: Cued and Uncued) and Eye Movement Task (between: Prosaccade and Antisaccade). The ANOVA on RT revealed a main effect of Cueing $[F(1,38)=5.60, p=0.02$, ges $=0.007$ ], where observers were slower to respond to targets at cued locations $(M=664 \mathrm{~ms})$ than at uncued locations $(M=$ $654 \mathrm{~ms})$. Neither the main effect of Eye Movement Task [ $F(1$, $38)=0.006, p=0.94$, ges $<0.001]$, nor the interaction between Cueing and Eye Movement Task $[F(1,38)=0.04, p=0.84$, ges $<0.001]$ were significant.

The same factorial ANOVA on accuracy revealed no main effect of Cueing on accuracy $[F(1,38)=0.90, p=0.35$, ges $=$ $0.003]$ and no effect of Eye Movement Task $[F(1,38)=1.04$, $p=0.31$, ges $=0.02]$. Importantly, a significant interaction between Cueing and Eye Movement Task was observed $[F(1,38)=5.94, p=0.02$, ges $=0.017]$ : observers were more accurate responding to cued than to uncued targets in the Prosaccade condition $(+1.5 \%)$ and less accurate responding to cued than to uncued targets in the Antisaccade condition ($0.9 \%)$. The relationship between speed and accuracy across conditions is shown in Fig. 4.

\footnotetext{
${ }^{1}$ This exclusion is practically motivated. No errors makes it impossible to detect the direction of performance in SAT space that is the focus of this experiment (see Fig. 1).
} 


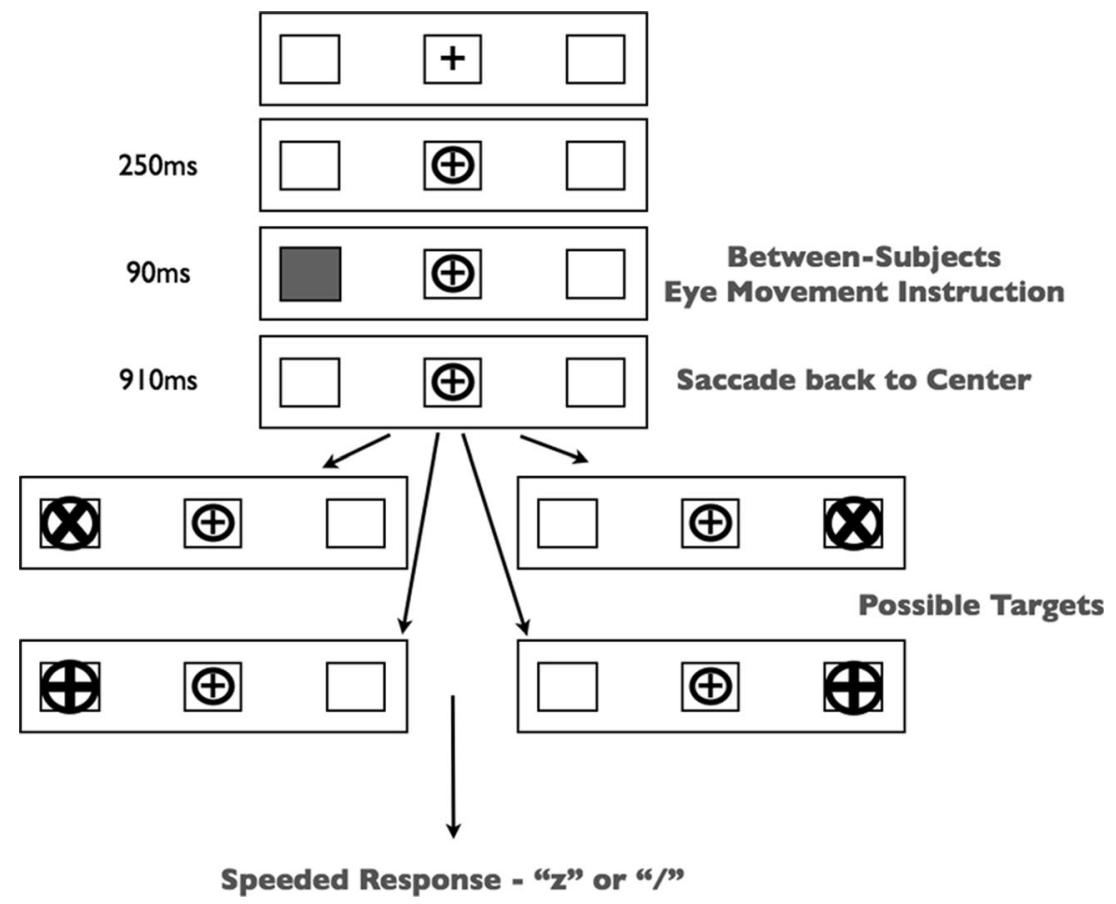

Fig. 3 Methods figure depicting the time course of a trial. Duration of each subsequent event is depicted to the left of the image. The between-subjects manipulation required either a prosaccade or antisaccade relative to the location of the cue

\section{Discussion}

Many have suggested that eye movements fundamentally alter the type of IOR (see Introduction). In both our conditions participants were required to make eye movements, yet two patterns of IOR were observed. Consistent with output-based IOR, prosaccades led to slower but more accurate responses at the cued relative to the uncued location. A different pattern was obtained when observers made antisaccades. Here, the inhibitory after-effect manifested as a cost in both RT and accuracy: viz., a genuine decrease in processing efficiency at the cued location. Notably, the magnitude of the inhibitory effect on RT did not differ between saccade conditions. This dissociation is further reinforced by a three-way interaction between Cueing, Eye Movement Task and the Simon effect (see Appendix B).

The findings in the prosaccade condition thus accord with those of Chica et al. (2010), in which color rather than shape discrimination was required. But going a step further, the absence of an SAT in the antisaccade condition dispels an ambiguity in the Chica et al. study concerning whether overt
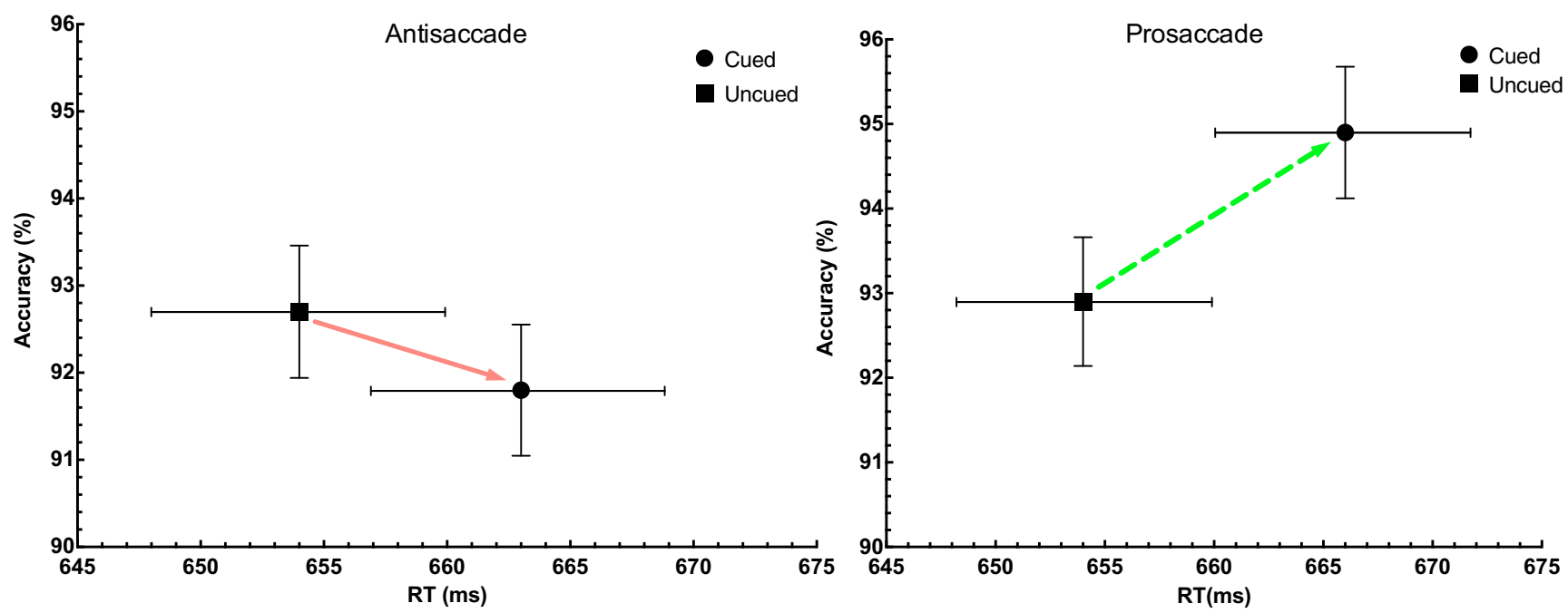

Fig. 4 Results demonstrating the effect of Cueing between Eye Movement Tasks in SAT space. Error bars represent Fisher's Least-Significant Difference 
orienting responses are sufficient for output-based IOR. By demonstrating that the critical factor for determining the form of inhibition is not whether overt orienting responses are involved (i.e., Taylor \& Klein, 2000), but rather whether eye movements are permitted toward the source of stimulation, the data support the proposal that input-based forms of IOR occur when the oculomotor response system responsible for reflexively generated saccades is in a tonically suppressed state (Klein \& Hilchey, 2011; see also Hilchey, Klein, \& Satel, 2014). Here we have shown dissociable effects on information processing efficiency, which converge with the findings of Hilchey, Dohmen, Crowder and Klein (2016), who demonstrated a dissociation based on how these effects can be measured. As in the present study, their observers were required to generate either a prosaccade or antisaccade at the time of a spatially uninformative peripheral cue. Following this first signal, their observers were required to make a manual response to indicate the direction of an arrow (left or right) presented at fixation. They found that when required to generate a prosaccade at the time of the cue, observers were slower to make responses in the direction of the original cue, an effect consistent with an output form of inhibitory effect (because no target was presented in the periphery, where it might suffer from an input-based inhibitory effect). However, when required to generate an antisaccade at the time of the cue, there was no discernible effect of the cue on responding. Notably, Hilchey et al. inferred this dissociation from the presence of an inhibitory effect in the prosaccade condition paired with the absence of an inhibitory effect in the antisaccade condition. Our data, however, provide evidence on the dissociable inhibitory consequences for the two forms of IOR. These converging investigations, as well as those of Taylor and Klein, provide the subsequent theoretical conceptualization: the output effect seems to be about the direction of the orienting response relative to the cue, and is not an effect on perceptual processes nor the accumulation of information about the target. Contrarily, the input effect seems to be about where the target is presented relative to the cue because the effect can only be measured with a spatially overlapping peripheral target, and consequently is not an effect on motoric processes but instead a cost in information processing efficiency.

Readers might interpret our patterns simply as a consequence of generating an overt orienting response. The 'Cueing by Eye Movement Type' interaction shows enhanced accuracy at the location to which an eye movement was made, and a cost in RT at the location of the cue. Also, the Simon effect (Appendix B) is attenuated at the location to which the observer had moved their eyes. We believe this explanation of the present findings is unsound, because it is implausible that observers in the 'ignore' condition in Chica et al. (2010), or in any of the studies reported in the mega-analysis shown in Fig. 5A (Appendix B), were performing antisaccades at the time of the cue.
Our results clearly dissociate two inhibitory mechanisms, and demonstrate different interactions between each inhibitory effect (input and output) and the Simon effect. When the reflexive oculomotor system is suppressed, a cost in information processing efficiency is seen at the cued location. However, when the reflexive oculomotor system is engaged, responding is delayed without a cost in information processing efficiency. Klein and Redden (2016) have suggested that both of these effects could accomplish the novelty-seeking function attributed to IOR in the paper by Posner et al. (1985) - albeit by different means. The input form is assumed to decrease the salience of recently attended objects in a salience map, whereas the output form biases orienting behaviors against previously attended locations in a priority map.

Acknowledgments This work was supported by a Natural Sciences and Engineering Research Council operating grant awarded to Raymond Klein.

\section{Appendix A}

\section{References for Figure 2}

Cheal, M., \& Chastain, G. (1999). Inhibition of return: Support for generality of the phenomenon. The Journal of General Psychology, 126(4), 375-390.

Chica, A. B., Taylor, T. L., Lupiañez, Y., \& Klein, R. M. (2010). Two mechanisms underlying inhibition of return. Experimental Brain Research, 201, 25-35. doi:10.1007 /s00221-009-2004-1

Colzato, L. S., \& Hommel, B. (2009). Recreational use of cocaine eliminates inhibition of return. Neuropsychology, 23(1), 125.

Gutiérrez-Domínguez, F. J., Pazo-Álvarez, P., Doallo, S., Fuentes, L. J., Lorenzo-López, L., \& Amenedo, E. (2014). Vertical asymmetries and inhibition of return: Effects of spatial and non-spatial cueing on behavior and visual ERPs. International Journal of Psychophysiology, 91(2), 121-131.

Kingstone, A., \& Pratt, J. (1999). Inhibition of return is composed of attentional and oculomotor processes. Perception \& Psychophysics, 61(6), 1046-1054.

Langley, L. K., Fuentes, L. J., Hochhalter, A. K., Brandt, J., \& Overmier, J. B. (2001). Inhibition of return in aging and Alzheimers Disease: Performance as a function of task demands and stimulus timing. Journal of Clinical and Experimental Neuropsychology, 23(4), 431-446.

López-Ramón, M. F., Chica, A. B., Bartolomeo, P., \& Lupiáñez, J. (2011). Attentional orienting and awareness: Evidence from a discrimination task. Consciousness and Cognition, 20(3), 745-755.

Lupiáñez, J., Milán, E. G., Tornay, F. J., Madrid, E., \& Tudela, P. (1997). Does IOR occur in discrimination tasks? 
Yes, it does, but later. Perception \& Psychophysics, 59(8), 1241-1254.

Lupiáñez, J., \& Milliken, B. (1999). Inhibition of return and the attentional set for integrating versus differentiating information. The Journal of General Psychology, 126(4), 392-418.

Lupiáñez, J., Milliken, B., Solano, C., Weaver, B., \& Tipper, S. P. (2001). On the strategic modulation of the time course of facilitation and inhibition of return. The Quarterly Journal of Experimental Psychology: Section A, 54(3), 753773.

Madrid, E., Castillo, J. L., Weaver, B., \& Tipper, S. P. (2001). The effects of practice on cueing in detection and discrimination tasks. Psicológica: Revista de metodología y psicología experimental, 22(1), 1-24.

Martín-Arévalo, E., Chica, A. B., \& Lupiáñez, J. (2013). Task dependent modulation of exogenous attention: Effects of target duration and intervening events. Attention, Perception, \& Psychophysics, 75(6), 1148-1160.

Martín-Arévalo, E., Chica, A. B., \& Lupiáñez, J. (2014). Electrophysiological modulations of exogenous attention by intervening events. Brain and Cognition, 85, 239-250.

Mathôt, S., Dalmaijer, E., Grainger, J., \& Van der Stigchel, S. (2014). The pupillary light response reflects exogenous attention and inhibition of return. Journal of Vision, 14(14), 7-7.

Pratt, J., Kingstone, A., \& Khoe, W. (1997). Inhibition of return in location-and identity-based choice decision tasks. Perception \& Psychophysics, 59(6), 964-971.

Sanabria, D., Morales, E., Luque, A., Gálvez, G., Huertas, F., \& Lupiañez, J. (2011). Effects of acute aerobic exercise on exogenous spatial attention. Psychology of Sport and Exercise, 12(5), 570-574.

Taylor, T. L., \& Donnelly, M. P. (2002). Inhibition of return for target discriminations: The effect of repeating discriminated and irrelevant stimulus dimensions. Perception \& Psychophysics, 64(2), 292-317.

Taylor, T. L., \& Therrien, M. E. (2005). Inhibition of return for faces. Perception \& Psychophysics, 67(8), 1414-1422.

Theeuwes, J., \& Van der Stigchel, S. (2009). Saccade trajectory deviations and inhibition-of-return: Measuring the amount of attentional processing.Vision Research, 49(10), 1307-1315.

\section{Appendix B}

We see the present experimental design as an opportunity to evaluate the relationship between IOR, the Simon effect and eye movements. In a non-spatial 2-AFC task, the Simon effect refers to the performance advantage for responses that spatially correspond with the location of the target (Simon corresponding) relative to responses that do not correspond
(Simon non-corresponding). Previously, Ivanoff, Klein and Lupiañez (2002) showed (via a mega-analysis of the subjectby-subject data from 12 experiments) that IOR increases the Simon effect (see Fig. 5A; see also Hilchey et al., 2011). However, since the mega-analysis of Ivanoff et al. (2002) focused specifically on an inhibition that was ostensibly generated in the context of covert orienting, in the present overt orienting context, we can explore whether the relationship between IOR and the Simon effect is modulated by the activation state of the reflexive oculomotor system.

\section{Results}

To explore how task and cueing interact with the Simon effect, a $2 \times 2 \times 2$ mixed ANOVA was conducted for RT on Cueing (within: Cued and Uncued), Eye Movement Task (between: Prosaccade and Antisaccade), and Simon correspondence (within: Corresponding and Non-corresponding). This revealed a main effect of Simon correspondence $[F(1,38)=$ $4.45, p=0.04$, ges $=0.008]$, and no significant two-way interactions. However there was a significant three-way interaction among these factors $[F(1,38)=8.12, p<0.01$, ges = 0.007], where Cueing enhances and reduces the Simon effect in the Antisaccade and Prosaccade tasks, respectively. This pattern is represented in Fig. 5B and C.

\section{Discussion}

We had the opportunity to evaluate how the two forms of inhibitory cueing effect might differentially modulate the Simon effect. This investigation demonstrates that when an input effect is generated, the Simon effect is enhanced for targets appearing at the location of the cue. Inversely, when an output effect is generated, the Simon effect is attenuated when targets appear at the location of the cue. This interaction (Fig. 5B, C) among the Simon effect, cueing and the activation state of the reflexive oculomotor system is noteworthy. As suggested by Hilchey et al. (2011), the input effect augments the Simon effect at the cued location by delaying both the task-relevant identity S-R code, and to a greater extent the task-irrelevant location S-R code. In contrast, the output effect leads to an attenuation of the Simon effect at the cued location, perhaps by delaying responses until after the decay of prepotent Simon activation (Ivanoff, Klein, \& Lupiañez, 2002Fig. 4B). In the literature, the interaction between the Simon effect and cueing has not been a robust one. Indeed, it was observed only when individual studies were aggregated into a mega-analysis (cf. Ivanoff et al., 2002). An explanation for the non-robustness is suggested by the present findings: perhaps, within studies, the two interactions we have observed here were both in operation, but to different degrees. This may have occurred because some subjects made eye movements or because, within subjects, the reflexive oculomotor response 

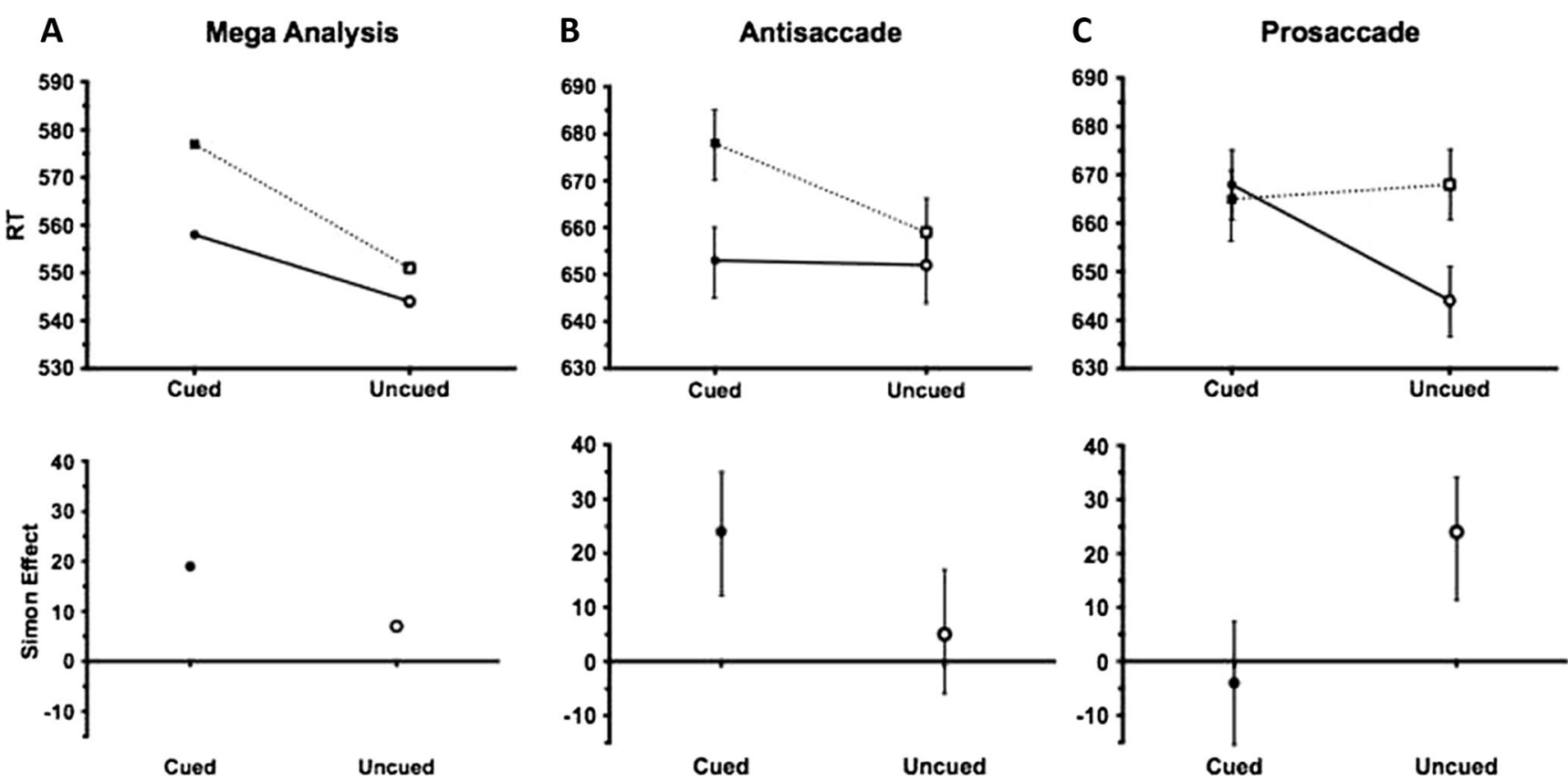

Fig. 5 A Mean reaction time (in ms) from 159 participants analyzed by Ivanoff et al., 2002 as a function of cue condition and spatial correspondence. These data are from the 1,000-ms cue-target SOA condition. RT data from the present experiment for Antisaccade (B) and Prosaccade (C) eye movement instructions for Cueing split across spatial

correspondence. For each upper panel, Simon Compatible is represented with the solid line and Simon Incompatible with the dotted line. The lower panels represent the Simon effect (with $95 \%$ confidence intervals for the estimate for $\mathbf{B} \& \mathbf{C}$ )

system was not in a tonically suppressed state. It bears noting that only one of the 12 experiments included in the megaanalysis reported monitoring eye movements or actively discouraging oculomotor responding (Lupiáñez et al., 1997Experiment 5).

\section{References}

Bourgeois, A., Chica, A. B., Migliaccio, R., de Schotten, M. T., \& Bartolomeo, P. (2012). Cortical control of inhibition of return: Evidence from patients with inferior parietal damage and visual neglect. Neuropsychologia, 50(5), 800-809.

Bourgeois, A., Chica, A. B., Valero-Cabré, A., \& Bartolomeo, P. (2013). Cortical control of inhibition of return: Exploring the causal contributions of the left parietal cortex. Cortex, 49(10), 2927-2934.

Chica, A. B., Taylor, T. L., Lupiañez, Y., \& Klein, R. M. (2010). Two mechanisms underlying inhibition of return. Experimental Brain Research, 201, 25-35. doi:10.1007/s00221-009-2004-1

Everling, S., Dorris, M. C., Klein, R. M., \& Munoz, D. P. (1999). Role of primate superior colliculus in preparation and execution of antisaccades and pro-saccades. Journal of Neuroscience, 19, 2740 2754.

Fecteau, J. H., Au, C., Armstrong, I. T., \& Munoz, D. P. (2004). Sensory biases produce alternation advantage found in sequential saccadic eye movement tasks. Experimental Brain Research, 159(1), 84-91.

Fischer, M. H., Pratt, J., \& Neggers, S. F. (2003). Inhibition of return and manual pointing movements. Perception \& Psychophysics, 65(3), 379-387.

Forbes, K., \& Klein, R. M. (1996). The magnitude of the fixation offset effect with endogenously and exogenously controlled saccades. Journal of Cognitive Neuroscience, 8(4), 344-352.

Gabay, S., Henik, A., \& Gradstein, L. (2010). Ocular motor ability and covert attention in patients with Duane Retraction Syndrome. Neuropsychologia, 48(10), 3102-3109.

Hartley, A. A., \& Kieley, J. M. (1995). Adult age differences in the inhibition of return of visual attention. Psychology and Aging, 10(4), 670.

Hilchey, M. D., Dohmen, D., Crowder, N. A., \& Klein, R. M. (2016). When is inhibition of return input-or output-based? It depends on how you look at it. Canadian Journal of Experimental Psychology/Revue Canadienne de Psychologie Experimentale. doi:10.1037/cep0000075

Hilchey, M. D., Hashish, M., MacLean, G. H., Ivanoff, J., Satel, J., \& Klein, R. M. (2014). On the role of eye movement monitoring and discouragement on inhibition of return in a go no-go task. Vision Research, 96, 133-139. doi:10.1016/j.visres.2013.11.008

Hilchey, M. D., Ivanoff, J., Taylor, T. L., \& Klein, R. M. (2011). Visualizing the temporal dynamics of spatial information processing responsible for the Simon effect and its amplification by inhibition of return. Acta Psychologica, 136(2), 235-244.

Hilchey, M. D., Klein, R. M., \& Ivanoff, J. (2012). Perceptual and motor IOR: Components or flavors? Attention, Perception, \& Psychophysics, 74, 1416-1429. doi:10.3758/s13414-012-0332-x

Hilchey, M. D., Klein, R. M., \& Satel, J. (2014). Returning to "inhibition of return" by dissociating long-term oculomotor ior from short-term sensory adaptation and other nonoculomotor "inhibitory" cueing effects. Journal of Experimental Psychology: Human Perception and Performance, 40(4), 1603-1616.

Hunt, A. R., \& Kingstone, A. (2003). Inhibition of return: Dissociating attentional and oculomotor components. Journal of Experimental Psychology: Human Perception and Performance, 29(5), 1068.

Ignashchenkova, A., Dicke, P. W., Haarmeier, T., \& Thier, P. (2004). Neuron-specific contribution of the superior colliculus to overt and covert shifts of attention. Nature Neuroscience, 7, 56-64. 
Ivanoff, J., \& Klein, R. M. (2006). Inhibition of return: Sensitivity and criterion as a function of response time. Journal of Experimental Psychology: Human Perception and Performance, 32(4), 908.

Ivanoff, J., Klein, R. M., \& Lupiañez, J. (2002). Inhibition of return interacts with the Simon effect: An omnibus analysis and its implications. Perception \& Psychophysics, 64, 318-327. doi:10.3758/BF03195794

Kingstone, A., \& Pratt, J. (1999). Inhibition of return is composed of attentional and oculomotor processes. Perception \& Psychophysics, 61(6), 1046-1054.

Klein, R. M., \& Hilchey, M. D. (2011). Oculomotor inhibition of return. In S. Liversedge, I. D. Gilchrist, \& S. Everling (Eds.), The Oxford handbook of eye movements (pp. 471-492). Oxford: Oxford University Press.

Klein, R. M., \& Redden, R. S. (2016). How “Inhibition of return" biases orienting. In T. Hubbard (Ed.), Spatial biases in cognition. Cambridge: Cambridge University Press.

Klein, R. M., \& Taylor, T. L. (1994). Categories of cognitive inhibition, with reference to attention. In D. Dagenbach \& T. Carr (Eds.), Inhibitory processes in attention, memory, and language (pp. 113150). San Diego: Academic Press.

Lupiáñez, J., Milán, E. G., Tornay, F. J., Madrid, E., \& Tudela, P. (1997). Does IOR occur in discrimination tasks? Yes, it does, but later. Perception \& Psychophysics, 59(8), 1241-1254.
Posner, M. I., \& Cohen, Y. (1984). Components of visual orienting. In H. Bouma \& D. G. Bouwhuis (Eds.), Attention and performance X: Control of language processes (pp. 531-556). Hove: Erlbaum.

Posner, M. I., Rafal, R. D., Choate, L., \& Vaughan, J. (1985). Inhibition of return: Neural basis and function. Cognitive Neuropsychology, 2, 211-228. doi:10.1080/02643298508252866

Rafal, R., Egly, R., \& Rhodes, D. (1994). Effects of inhibition of return on voluntary and visually guided saccades. Canadian Journal of Experimental Psychology/Revue Canadienne de Psychologie Expérimentale, 48, 284-300. doi:10.1037/1196-1961.48.2.284

Redden, R.S. (2016). Two Forms of Inhibition of Return Dissociated by Reflexive Oculomotor Engagement (Master's Thesis). Retrieved from DalSpace. (hdl.handle.net/10222/71304).

Sumner, P., Nachev, P., Vora, N., Husain, M., \& Kennard, C. (2004). Distinct cortical and collicular mechanisms of inhibition of return revealed with S cone stimuli. Current Biology, 14(24), 2259-2263.

Taylor, T. L., \& Klein, R. M. (2000). Visual and motor effects in inhibition of return. Journal of Experimental Psychology: Human Perception and Performance, 26, 1639-1656. doi:10.1037/00961523.26.5.1639

Terry, K. M., Valdes, L. A., \& Neill, W. T. (1994). Does "inhibition of return" occur in discrimination tasks? Perception \& Psychophysics, 55(3), 279-286.

Zhang, Y., \& Zhang, M. (2011). Spatial working memory load impairs manual but not saccadic inhibition of return. Vision Research, 51(1), $147-153$. 